\title{
Role of soil moisture in the amplification of climate warming in the eastern Mediterranean and the Middle East
}

\author{
George Zittis $^{1, *}$, Panos Hadjinicolaou ${ }^{1}$, Jos Lelieveld ${ }^{1,2}$ \\ ${ }^{1}$ Energy Environment and Water Research Center, The Cyprus Institute, 1645 Nicosia, Cyprus \\ ${ }^{2}$ Department of Atmospheric Chemistry, Max Plank Institute for Chemistry, 55020 Mainz, Germany
}

\begin{abstract}
Projections for the 21st century suggest that climate change will be associated with changes in the frequency and intensity of weather and climate extremes (e.g. heat waves, droughts, heavy precipitation events). In the already warm summertime eastern Mediterranean and Middle East (EMME) climate change may involve mechanisms and feedbacks that cause or intensify hot weather events. A potentially important feedback mechanism involves soil moistureatmosphere interactions. When the soil water content and evapotranspiration are decreased, nearsurface air temperatures are enhanced due to reduced evaporative cooling. Here we show the importance of this mechanism, especially in the northern part of the EMME, using the output of a regional climate model (HadRM3P). We applied the classical hydrology framework to define evapotranspiration regimes as a function of soil moisture and latent heat fluxes. Further, we used the correlation of summer maximum temperature and evapotranspiration as a diagnostic of this coupling, and we performed a composite analysis of maximum temperature for the dry and wet years of our dataset. Since temperature and precipitation regimes are expected to change in the EMME, we considered alterations of the relationship between soil moisture and the maximum temperature throughout the 21 st century.
\end{abstract}

KEY WORDS: Land-atmosphere interactions - Soil moisture - Summer temperature $\cdot$ HadRM3P · Regional climate model $\cdot$ Eastern Mediterranean-Middle East

Resale or republication not permitted without written consent of the publisher

\section{INTRODUCTION}

The latest Assessment and Special Reports of the Intergovernmental Panel on Climate Change (IPCC 2007, Seneviratne et al. 2012) suggest that since 1950 the number and intensity of heat waves have generally increased and warm nights have become more frequent over most land areas. IPCC climate projections indicate that this trend is very likely to continue in the 21st century. The recent European heat waves of 2003 and 2007, in Russia in 2010 and in the USA in 2012 seem to corroborate that these events are expressions of global warming on a regional level. Barriopedro et al. (2011) characterizes the 2003 and 2010 events as 'mega-heatwaves', indicating that these cases likely broke the $500 \mathrm{yr}$ seasonal temperature records over approximately $50 \%$ of Europe. Increased mortality, energy and water shortages and crop failures are some of the main impacts of heat waves, which may be more widespread than other severe weather phenomena (Klinenberg 2002). Additionally, as the global population grows (United Nations 2011) and urbanization continues (Grimm et al. 2008), the impacts of extreme heat events may be further amplified, due to the urban heat island effect (Conti et al. 2005, Laaidi et al. 2011) and urban air pollution (Solberg et al. 2008, Tressol et al. 2008).

The occurrence and intensity of such events are related to general circulation patterns and certain atmospheric flow anomalies (Black et al. 2004, 
Meehl \& Tebaldi 2004, Fink et al. 2004, Kenyon \& Hegerl 2008, Grumm 2011). However, a number of studies indicate that atmospheric circulation alone cannot always explain temperature anomalies (Seneviratne et al. 2006b, Efthymiadis et al. 2011, Feudale \& Shukla 2011). Factors that may amplify extreme heat events can include soil-moisture feedbacks (Seneviratne et al. 2006b, Fischer et al. 2007, Seneviratne et al. 2010, Hirschi et al. 2010, Jaeger \& Seneviratne 2011, Mueller \& Seneviratne 2012, Quesada et al. 2012).

Particularly in the Mediterranean climate change 'hot-spot' (Giorgi 2006), the need for research on climate extremes is pressing. Significant positive trends in temperature extremes in the region are indicated by a number of studies (Kostopoulou \& Jones 2005, Kuglitsch et al. 2010, Efthymiadis et al. 2011, Lelieveld et al. 2012, Tanarhte et al. 2012), and intensification of heat stress is very likely to continue throughout the 21st century (Sánchez et al. 2004, Diffenbaugh et al. 2007, Fischer \& Schär 2010, Lelieveld et al. in press).

Regional climate projections based on the HadRM3P model (Jones et al. 2004) for the end of the 21 st century show relatively large increases in mean (not shown) and maximum temperatures (Fig. 1) in the northern part of our study area. In the same regions, significant decreases in precipitation amounts are found (Fig. 2). This combined regional heating and drying has motivated us to explore the role of soil moisture in the amplification of heat extremes in the eastern Mediterranean and the Middle East (EMME). In the present study we concentrated on the summer season, when the role of this feedback mechanism appears to be most important, and the occurrence of such events most common.

\section{CLIMATE MODELING DATA}

We used seasonal summer (June-August) data of the daytime maximum temperature at $1.5 \mathrm{~m}$ above the ground $\left(T_{\max }\right)$, surface latent heat flux (LE), net radiation $\left(R_{\mathrm{n}}\right)$, soil moisture in the root zone expressed as the degree of saturation $(W)$, evapotranspiration (ET) and precipitation $(P)$. Unfortunately, there are no reliable and consistent_-in time and space - observational datasets of most of the abovementioned variables available (Seneviratne et al. 2006a, Mueller et al. 2011, Tanarhte et al. 2012), and therefore we used model data to study their potential importance for the region. The representativeness of the model output was tested by comparing with

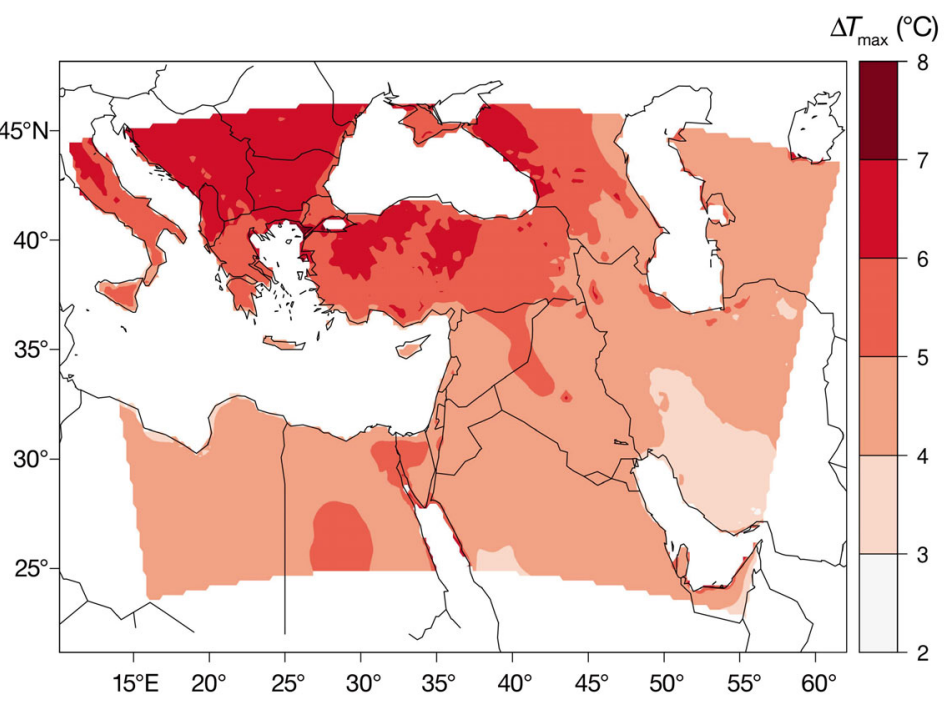

Fig. 1. Change of summer (June-August) maximum temperature (Scenario: 2050-2099 minus control: 1951-2000), based on regional climate change model simulations by Lelieveld et al. (2012) (see Section 2)

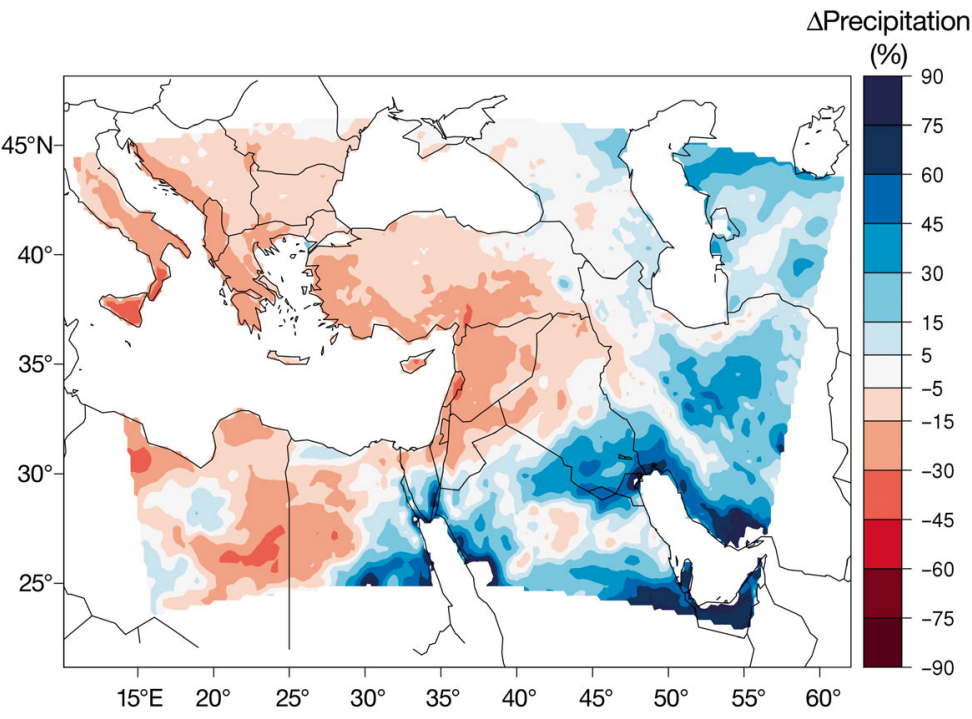

Fig. 2. Change of spring to summer (March-August) precipitation (scenario [SCN]: 2050-2099 minus control [CTL]: 1951-2000) (same data source as Fig. 1)

parameters for which measurements exist. The data were obtained from the Hadley Centre HadRM3P Regional Climate Model, used to dynamically downscale the HadCM3Q0 Atmosphere-Ocean General Circulation Model results to a $25 \times 25 \mathrm{~km}$ resolution over the EMME. The transient simulation covered the period 1951-2099 and for the future projection was forced by the Special Report on Emission Scenarios (SRES) intermediate A1B scenario (Nakicenovic et al. 2000).

For the simulation we used the MOSES (Met Office Surface Exchange Scheme) land-surface representa- 
tion (Cox et al. 1999). The near-surface temperature is derived from the surface energy balance as a diagnostic variable. The thermodynamic scheme simulates water phase changes in the soil. The vegetation canopy conductance interacts with the atmospheric flow, incoming radiation and precipitation and provides fluxes of heat and moisture to the atmosphere and rainfall runoff (Jones et al. 2004).

The regional HadRM3P output has been extensively compared against observations in the EMME and ensemble model output for the European part of the domain, with a focus on temperature, precipitation and weather extremes (Lelieveld et al. 2012, in press). The model has been shown to be in general agreement with the Climate Research Unit (CRU; Version TS3.0) gridded ground-based meteorological dataset, although it is somewhat cold-biased during winter and slightly warmer during the summer season. HadRM3P realistically simulates the extremes relevant to our study such as the number of consecutive dry days and the number of days with a $T_{\max }$ $>35^{\circ} \mathrm{C}$. A model inter-comparison of 9 regional climate models used in the ENSEMBLES project (www. ensembles-eu.org) indicates that our HadRM3P projection for locations in the EMME is somewhat warmer than the mean, but, overall, well within the ensemble mean range.

To investigate the impact of climate change and the role of the above-mentioned soil-moisture feedback, we performed the analysis over 2 half-century periods, the control years (CTL: 1951-2000) and the future scenario projection (SCN: 2050-2099). These extensive half-century periods were selected to provide ample statistics on anomalously dry and wet years.

\section{METHODS}

\subsection{Evaporative regimes}

In addition to the changes in summer $T_{\max }$ and precipitation (Figs. $1 \& 2$ ) we also calculated the changes in soil moisture (saturation degree) and LE. To characterize this flux we used the evaporative fraction $(\mathrm{EF})$, which is defined as the ratio of seasonal LE to total seasonal $R_{\mathrm{n}}$.

Classical hydrology (Budyko 1958) defines 2 distinct evaporative regimes, the soil-moisturecontrolled and the energy-limited regime (Fig. 3). The first one encompasses relatively dry areas, where changes in soil moisture lead to changes in $\mathrm{ET}$, and the second, relatively wet ones, where ET

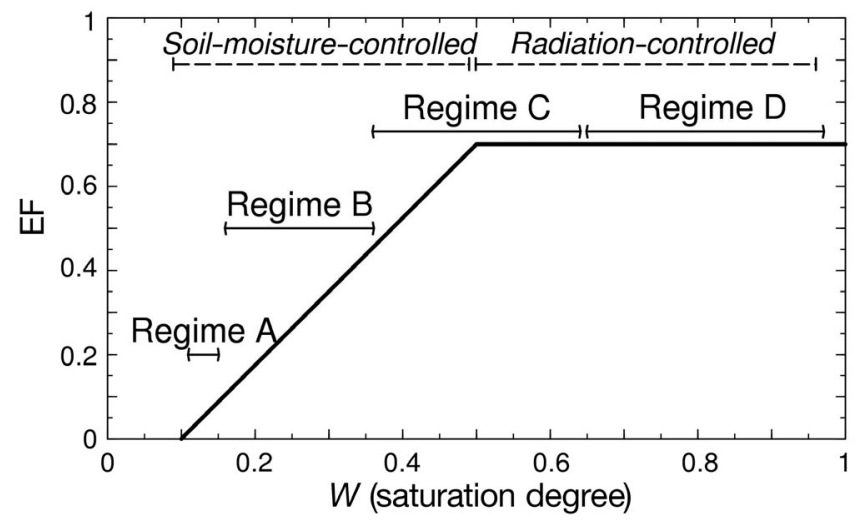

Fig. 3. Idealized relationship between the evaporative fraction $(\mathrm{EF})$ and soil moisture $(W)$ (redrawn from Koster et al. 2009), indicating the 4 regimes

is not sensitive to variations of the soil-moisture content and is controlled exclusively by the available energy through incoming radiation. Koster et al. (2009) proposed a refined classification of the evaporative regimes. Using the same basic concept, they suggest a division into 4 evaporative regions (Fig. 3). In Regime A, although part of the soilmoisture-controlled regime, the soil-moisture variation is generally too small to cause changes in the LE. Regime D, on the other hand, represents the wet energy-limited regime, where soil moisture is abundant and ET is controlled by radiation. Regime $B$ is the transitional regime, where increases (decreases) of soil moisture lead to increases (decreases) in EF and to relatively lower (higher) surface temperatures due to the degree of evaporative cooling. Regime C can act either as Regime B or D depending on the available water content in any particular period.

We applied Koster's method using slightly different thresholds, adjusted to our region of interest and the temporal extent of our data set. The classification was based on the relationship between EF and soil-moisture $(W)$ amounts and variability. We examined this relationship at the dry and wet ends of the soil-moisture distribution. $\mathrm{EF}_{\text {dry }}$ and $\mathrm{EF}_{\text {wet }}$ were defined as the values of standardized EF averaged over the driest and wettest years, respectively. As dry (wet) we considered the 10 individual years with summer soil moisture lower (higher) than the 20th (80th) percentile of each of the 2 sub-periods of our analysis (CTL and $\mathrm{SCN}) . \mathrm{EF}_{\text {dry }}$ should be nonzero when ET is sensitive to soil moisture, at least at the driest end (B and C regimes). Since both $\mathrm{EF}_{\text {dry }}$ and $\mathrm{EF}_{\text {wet }}$ are standardized anomalies, the value of their sum would be around zero only if ET is always sensitive to soil mois- 
ture (Regime B). The inter-annual standard deviation of the soil moisture is denoted as $\sigma_{w}$.

Based on Koster's classification, the 4 evaporative regimes were defined as:

Regime A: Interannual soil-moisture variations are too small to affect interannual temperature variations

$$
\sigma_{W}<0.02
$$

Regime B: June-August (JJA)-averaged ET usually lies in the soil-moisture-controlled regime

$$
\sigma_{W}>0.02
$$

$\left|E F_{\text {dry }}\right|>0.3$ (evaporation varies with soil moisture)

$\left|E F_{\text {dry }}+E_{\text {wet }}\right|<0.3$ (evaporation is always sensitive to soil moisture)

Regime C: JJA-averaged ET lies in the soilmoisture-controlled regime during some years and in the energy-controlled regime during other years

$$
\sigma_{W}>0.02
$$

$\left|E F_{\text {dry }}\right|>0.3$ (evaporation varies with soil moisture)

$\mid$ EFdry + EFwetl $>0.3$ (evaporation sensitive only on the dry end)

Regime D: JJA-averaged evaporation usually lies in the energy-controlled regime

$$
\sigma_{W}>0.02
$$

$$
\left|\mathrm{EF}_{\mathrm{dry}}\right|<0.3 \text { (evaporation does not vary with soil }
$$
moisture)

To explore how realistically our analysis represents observed conditions we compared our model results with the CRU (Version TS 3.1) dataset (Jones \& Harris 2008). We used precipitation as a proxy for soil moisture. Composites of the standard normal deviates of summer $T_{\max }$ and precipitation were computed for selected regions (averages of approximately $1^{\circ} \times 1^{\circ}$ areas), representing each evaporative regime. We followed the Koster et al. (2009) method for the calculation of the composites for both the model results and observational data. For our CTL period (1951-2000), the amount of summer precipitation was ranked and sub-divided into 10 deciles of 5 yr. $T_{\max }$ was averaged over each precipitation decile.

\subsection{Correlation analysis}

Another widely used diagnostic of the landatmosphere coupling is the correlation coefficient between ET and near-surface air temperature (Seneviratne et al. 2006b, 2010, Fischer \& Schär 2009, Jaeger et al. 2009). When ET is controlled by soil moisture, a strong anti-correlation is expected. On the other hand, when there is abundant soil moisture, and evaporation is controlled by atmospheric conditions, the correlation is positive. Low correlations indicate no coupling. Because of our interest in heat extremes, we used $T_{\max }$ instead of mean temperatures. We retained only the statistically significant correlations derived from the $\mathrm{p}$-values of the Pearson correlation test.

\subsection{Composite maps}

Composite analysis is a common statistical data analysis method in climate research used in the identification, description and understanding of processes (von Storch \& Zswiers 1999). Here, we created composite $T_{\max }$ maps for the wettest and driest cases to uncover the impact of soil-moisture extremes. $T_{\max }$ composites were produced from the differences between the 10 driest and the 10 wettest years for each time period. In regions not sensitive to the soilmoisture feedback, this difference should have small values around zero. In addition, to examine if temperature is more sensitive on the dry or wet end, we also present the deviation between dry and wet year averages and the 50 yr climatology of $T_{\max }$ over the 2 sub-periods.

\section{RESULTS}

\subsection{Climate change impact on soil moisture}

Fig. 4 illustrates the changes of soil moisture and EF between the CTL and SCN periods. The pattern of changes was similar to the changes in the mean temperature (not shown) and $T_{\max }$ (Fig. 1). Regions of stronger warming (Italy, the Balkans, Anatolia) matched regions of more intensive drying in terms of precipitation (Fig. 2) and soil moisture (Fig. 4, left panel). In the same regions the mean summertime LE was reduced (Fig. 4, right panel). These similarities in spatial patterns were a first indication of the possible linkage between changes in soil moisture and $T_{\max }$.

\subsection{Evaporative regimes}

The evaporative regimes derived from the HadRM3P model output for the 1951-2000 period are presented in the upper panel of Fig. 5. There was an 


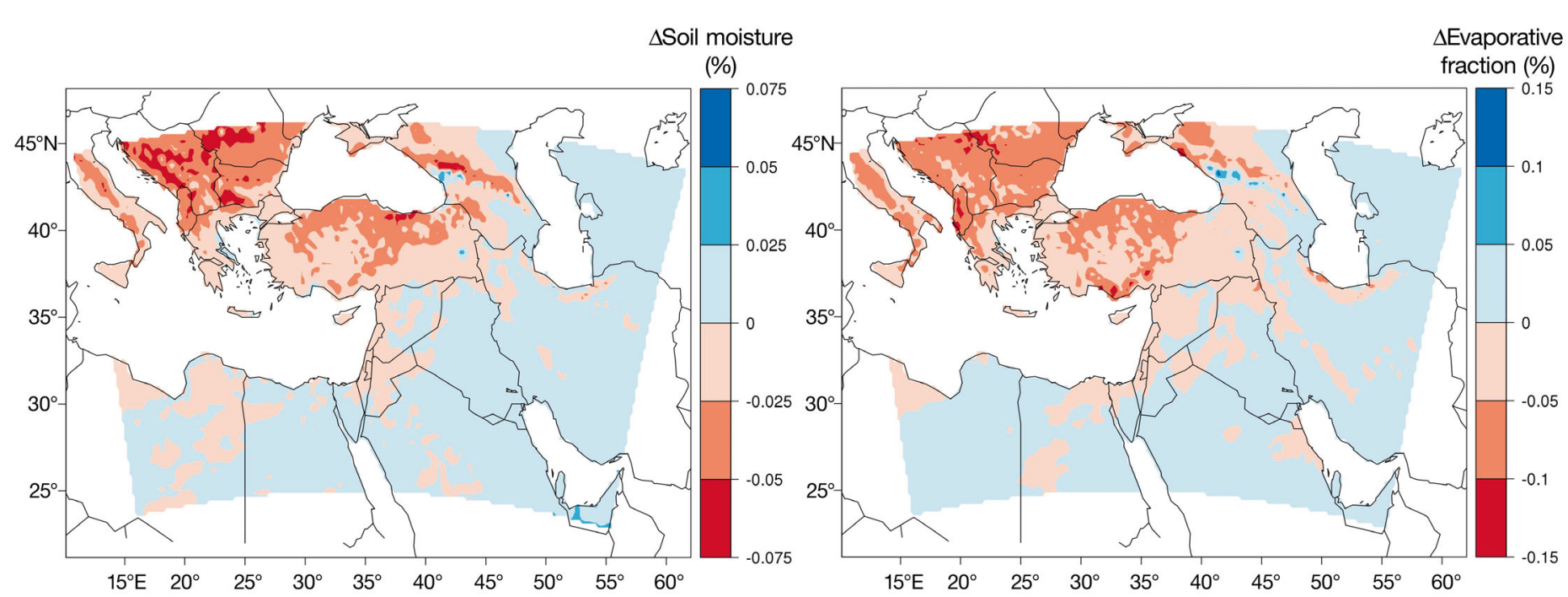

Fig. 4. Change in summer soil-moisture saturation degree (left) and in summer evaporative fraction (ratio of seasonal latent heat flux to total seasonal net radiation); scenario: 2050-2099 minus control: 1951-2000 (right)
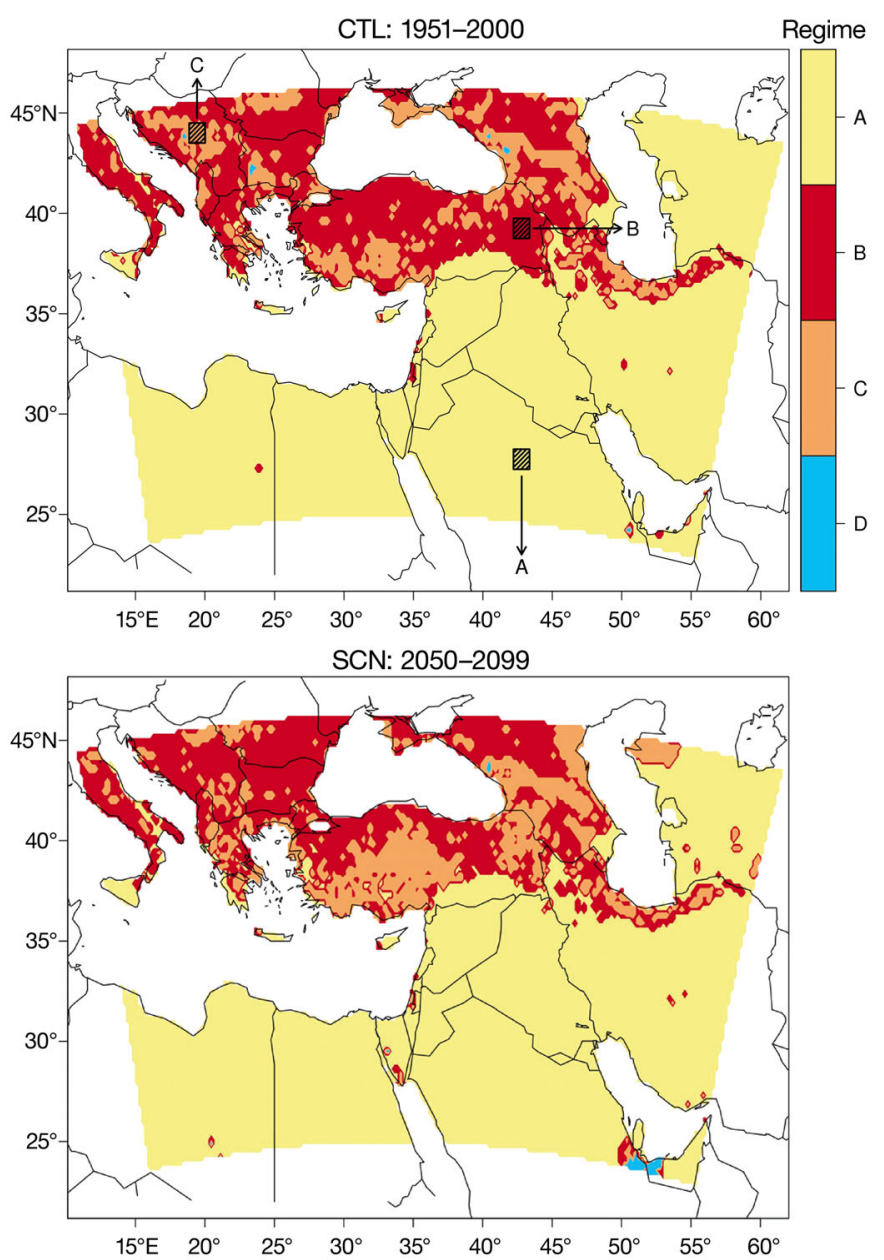

Fig. 5. Geographical distribution of evaporative regimes (A-D, see Fig. 1) on the basis of HadRM3P data for the control period (CTL, top) and for the future climate scenario (SCN, bottom). Shaded boxes (upper panel): areas used for comparison between model and observations (see Section 4.2 and Fig. 6 ) apparent north-south gradient, and in extended areas in the south there was no coupling between soil moisture and temperature (Regime A). This is not surprising, as the climate is arid to hyper-arid, and rainfall and soil moisture in summer are practically zero. In contrast, in the northern and relatively wetter part of the domain, ET can be controlled by soilmoisture variations (Regimes B \& C). The somewhat noisy distribution of $\mathrm{B}$ and $\mathrm{C}$ regime points might be a result of the sensitivity of the model to the forcing data and the connected uncertainties in simulating moisture-related variables; a different HadRM3P simulation of shorter length, forced by an atmosphere-only global model (HadAM3P) produced a slightly different distribution of B and C grid points, but with the overall picture remaining the same (not shown). Regions under Regime D, where soil moisture is always sufficient and ET can reach its potential values depending on the available radiation, appeared to be limited to very small areas at high elevation in the Caucasus Mountains and in the Balkans.

A comparison between the model and observational composites for June-August $T_{\max }$ and standardized precipitation anomalies is presented in Fig. 6. This shows how realistically the model represents the temperature sensitivity to moist conditions. The selected areas used for the calculations were representative of each evaporative regime and are shown in the upper panel of Fig. 5. Regime D was excluded from this analysis since its occurrence was not evident over extended areas, yielding insufficient statistics. The model generally captured the relationship between $T_{\max }$ and precipitation well, especially for the sensitive $\mathrm{B}$ and $\mathrm{C}$ regimes. In agreement with 

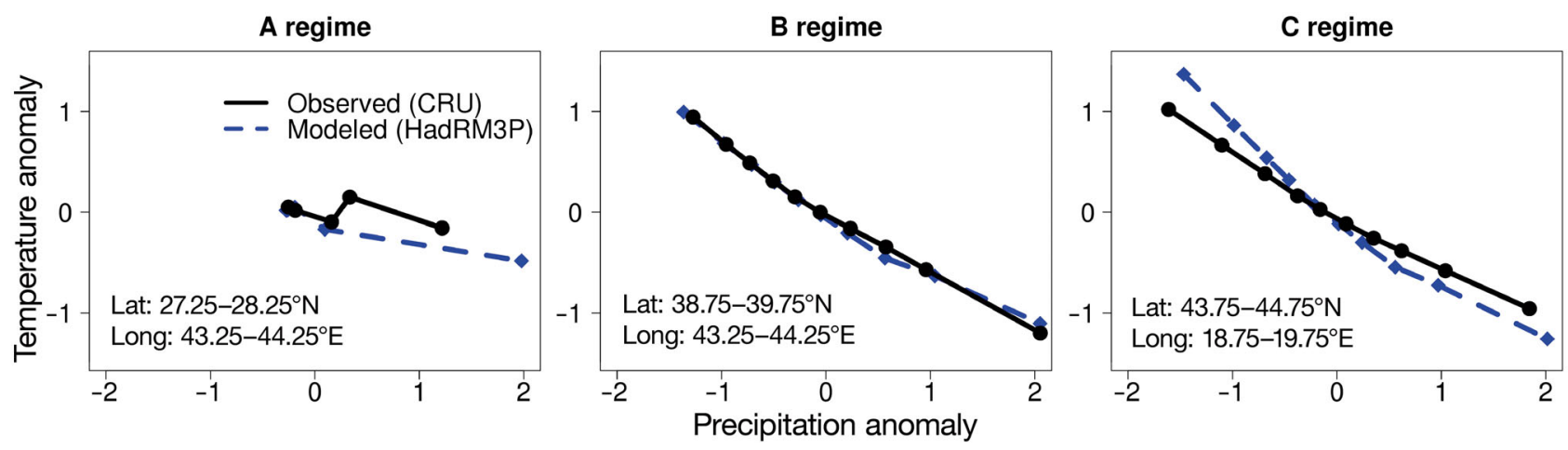

Fig. 6. Relationship between maximum temperature and precipitation expressed in terms of standard normal deviates according to the HadRM3P model (dashed blue line) and Climate Research Unit (CRU) observations (continuous black line)

the observations, positive $T_{\max }$ anomalies were expected during periods of low rainfall and vice versa. This connection was not evident over the dry A regime sample area.

To explore to what extent the spatial distribution of the evaporative regimes may change with time, we repeated the analysis for the SCN period (Fig. 5, lower panel) and compared with the previous results. Again, the most sensitive regions (Regimes B \& C) were found in the northern EMME. It appears that the basic pattern remains similar, as about $86 \%$ of all land grid points were categorized in the same evaporative regime for both time periods. Extended areas under Regime A remained in the southern EMME, in spite of the projected increase of precipitation (Fig. 2), which may have been large in percentage, but was too small in absolute terms to alter the regime.

The most common changes ( $73 \%$ of total) were those of grid points transforming from $B$ to $C$ regimes and vice versa. Shifts from C to B regimes were mainly found in the Balkans, in particular in Romania, the former Yugoslavia region and southwestern Bulgaria. These were the regions where the model projected the largest decreases in soil moisture (Fig. 4). On the other hand, changes from $\mathrm{B}$ to $\mathrm{C}$ regimes were projected mainly in central-northern Turkey. This shift was caused by an increase of EF anomalies during wet years $\left(\mathrm{EF}_{\text {wet }}\right)$ in the aforementioned region, which constitutes one of the regime classification criteria (not shown). The shift from the A to D regime in the area of the United Arab Emirates (UAE) was explained by an increase of soilmoisture variability. Note that the projected increase of precipitation in this area was a robust result of climate change modeling studies, explained by a northward extension of moist tropical weather influences (Lelieveld et al. 2012), being consistent with observed recent rainfall trends (Tanarhte et al. 2012).
The scatterplots of Fig. 7 corroborate the relationship between soil moisture and $T_{\max }$. They were drawn after calculation of the means of all grid points classified in each evaporative regime. As expected, the relation was stronger (statistically significant correlation coefficients at the $95 \%$ confidence level) for $\mathrm{B}$ and $\mathrm{C}$ regimes and remained unaltered for both time periods considered. Regime A grid points in the SCN period tended to increasingly represent the sensitive $B$ regime as a result of the precipitation increase over the Arabian Peninsula. The tendency of grid points in the D regime was probably biased by the small sample in our dataset, which limited the significance.

\subsection{Correlation analysis}

The correlation coefficients between ET and $T_{\max }$ for the 2 sub-periods are presented in Fig. 8. The significant correlations (95\% confidence level) are indicated with blue (positive) and red (negative) shading. For both periods, the strongest negative correlations were found in the Balkans, Turkey and the areas north and south of the Caucasus Mountains. These correlations suggest a strong coupling between soil moisture and temperature.

In general, this method provides results that are in agreement with the evaporative regime analysis in the previous section. Regions with strong negative correlations ( -0.6 up to -1 ) approximately matched the sensitive $\mathrm{B}$ and $\mathrm{C}$ regions of the evaporative regime classification. For the CTL period (Fig. 8, left panel), the northern part of the study area seemed to be most sensitive to this feedback mechanism. In the southern and eastern parts of the domain, correlations were close to zero and mostly not significant. 

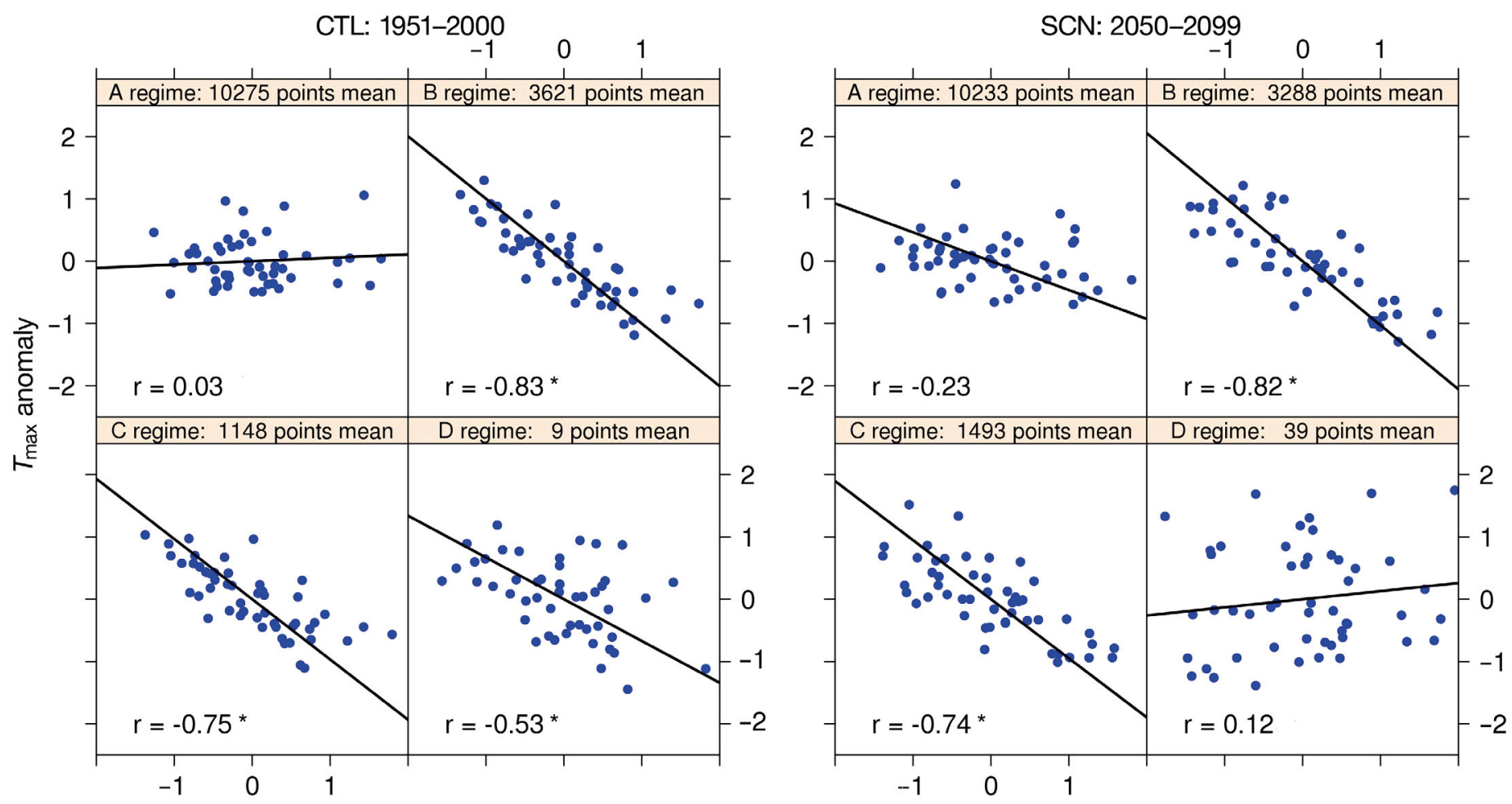

Soil-moisture anomaly

Fig. 7. Scatterplots of the relation between soil moisture and maximum temperature anomalies for the mean of all grid points of each regime group for the control period (CTL, left) and the future climate (SCN, right). In each panel, the regression lines and the correlation coefficients ( $\mathrm{r}$ ) are also shown, as well as the number of grid points that have contributed to the calculation of mean values. Significant correlations (95\% confidence level) are marked by an asterisk
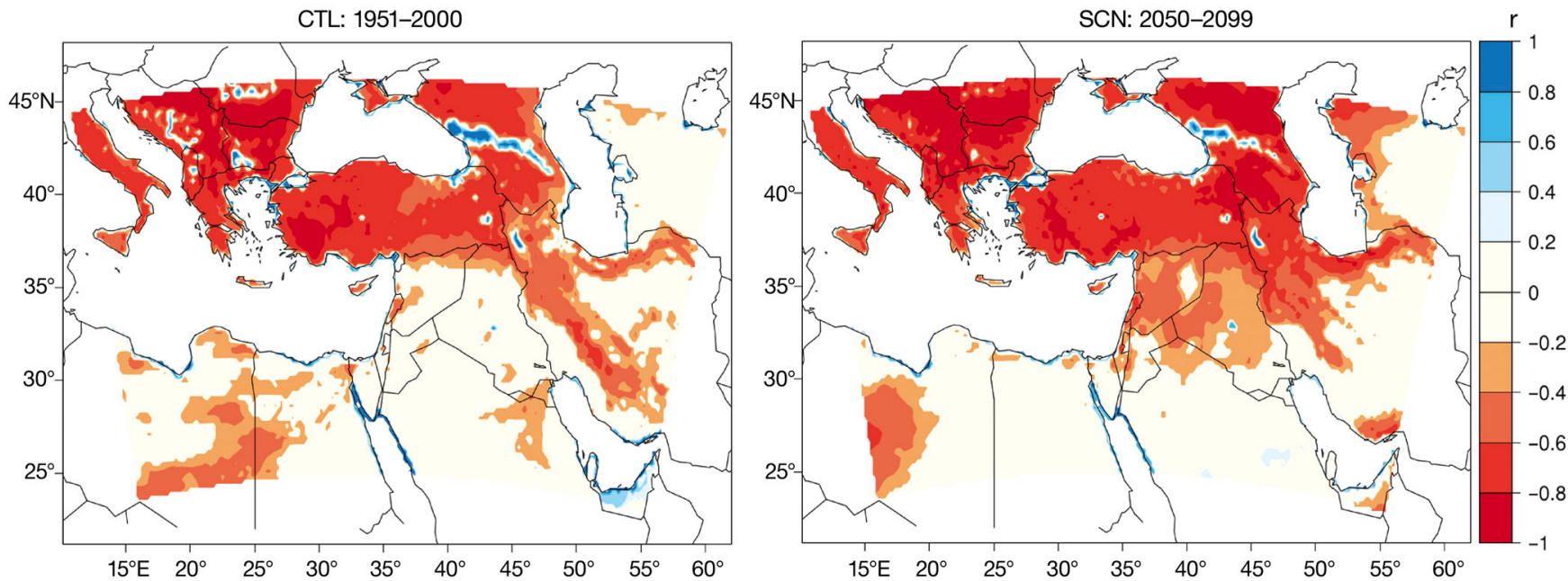

Fig. 8. Correlation coefficients between maximum temperature and evapotranspiration for the control period (CTL, left) and the future climate scenario (SCN, right). Significant correlations (95\% confidence level) are indicated in shades of red and blue according to the key

For the second half of the 21st century (Fig. 8, right panel), the highest anti-correlations were again found in the northern part of the EMME. Compared to the CTL period enhanced anti-correlations were projected in the Balkans and the regions north and south of the Caucasus. An expansion of negative correlations, but with less significant values for the future SCN period, was found towards the southeast, over Syria and Iraq, and further east along the east coast of the Caspian Sea. 


\subsection{Composite analysis}

The composites for the 2 selected periods are shown in Fig. 9. The southern part of our study area appeared to be insensitive, since the differences during the dry and wet years were negligible. On the other hand, in the northern EMME, the summer $T_{\max }$ differences $\left(2-8^{\circ} \mathrm{C}\right)$ in the composite maps indicated strong coupling between soil moisture and $T_{\max }$. Spatially the composites were projected to remain unaltered in the second half of the 21st century (cf. left and right panels in Fig. 9). However, changes in the magnitude of the differences were found in the northwestern Balkan area, southern Italy, regions south of the Caucasus, parts of Turkey and northern Iran. Over these regions this feedback appeared to be enhanced, as the difference in $T_{\max }$ between the dry and wet years was increased by up to $1-2^{\circ} \mathrm{C}$.

After calculating the dry and wet averages of $T_{\max }$ for the 2 sub-periods we present their differences from the corresponding 50 yr climatology (Fig. 10). As expected, in the southern EMME there were no significant deviations from the mean climate. This was the case for both the CTL and SCN periods. In contrast, in the more sensitive northern part of the EMME, warm anomalies $\left(1-4^{\circ} \mathrm{C}\right)$ occurred during dry years. The maximum of these anomalies was found in the Balkan region. On the other hand, during relatively wet years, $T_{\max }$ appeared to be up to $4^{\circ} \mathrm{C}$ lower than the long-term mean.

\section{DISCUSSION AND CONCLUSIONS}

The combination of the different model-based diagnostic methods of the soil moisture-air temperature coupling (classification in evaporative regimes, correlation and composite analysis) consistently suggested that the climate-change-related summer temperature increases were sensitive to variations in the soil water content, though only in the northern part of the EMME.

In Italy, the Balkans, Turkey and the region north and south of the Caucasus Mountains, soil-moisture deficits during dry years - possibly in addition to anticyclonic circulation patterns (Black et al. 2004, Fink et al. 2004, Meehl \& Tebaldi 2004, Grumm 2011) can potentially create or at least amplify extreme temperature conditions and contribute to heat waves. Our results were consistent with the study of Koster et al. (2009), though the latter authors did not compute or discuss the relevant regional details presented here. Our results were also consistent with the more recent observational studies of Hirschi et al. (2010; for southeastern Europe) and Mueller \& Seneviratne (2012; a global study), which identify the presence of feedbacks between moisture availability (assessed based on the standardized precipitation index) and temperature extremes in a part of the considered region.

According to our simulation, besides some localized transitions between the $\mathrm{B}$ and $\mathrm{C}$ grid points, the spatial distribution of projected evaporative regimes did not seem to change significantly throughout the 21st century. In view of our interest
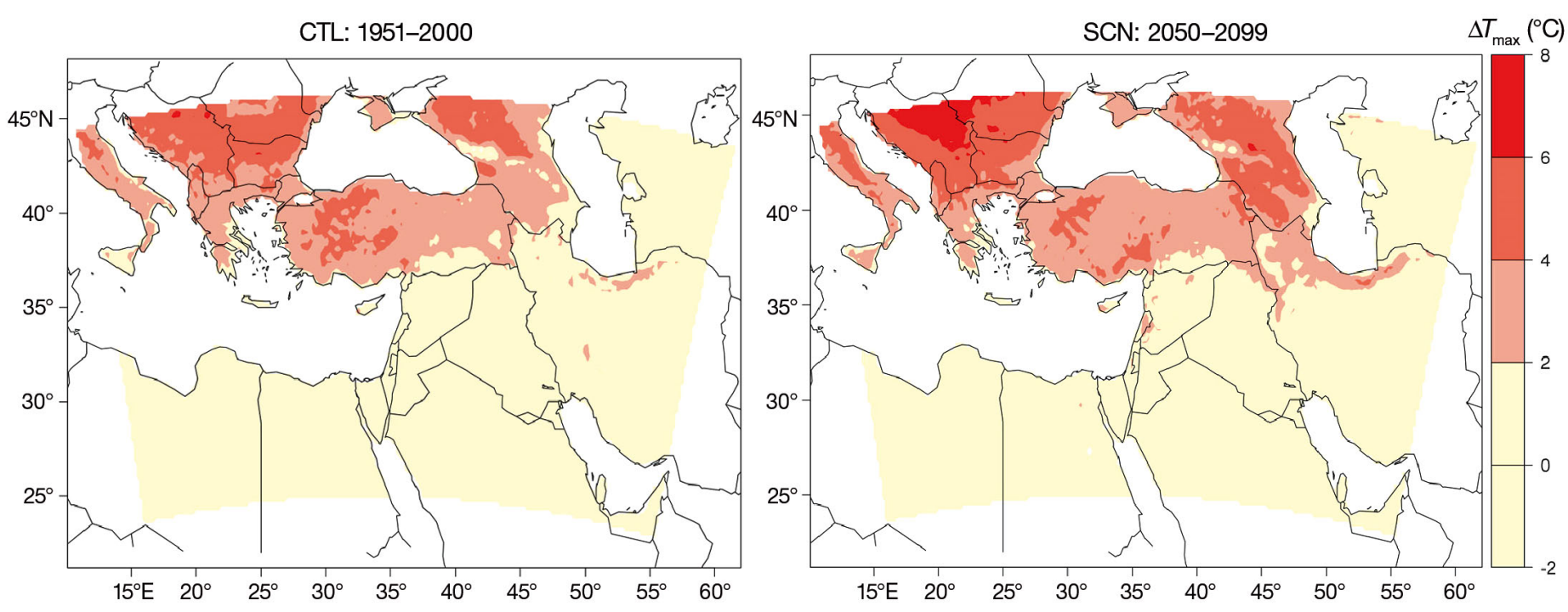

Fig. 9. Composite analysis of $T_{\max }$. The difference between the 10 driest and 10 wettest years is shown for the control period (CTL, left) and for the future climate scenario (SCN, right) 
Driest years minus 50 yr mean CTL: 1951-2000
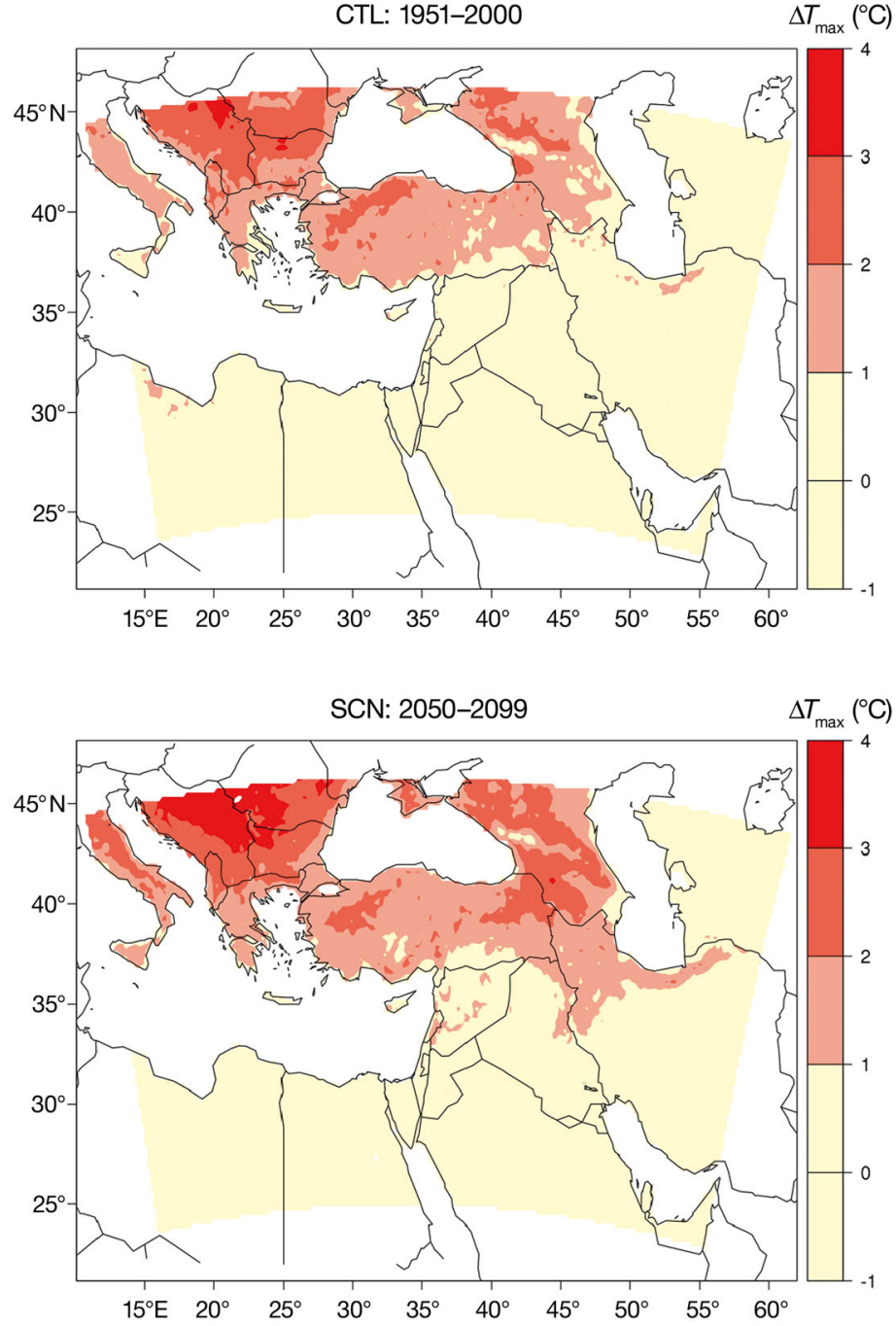

Wettest years minus 50 yr mean
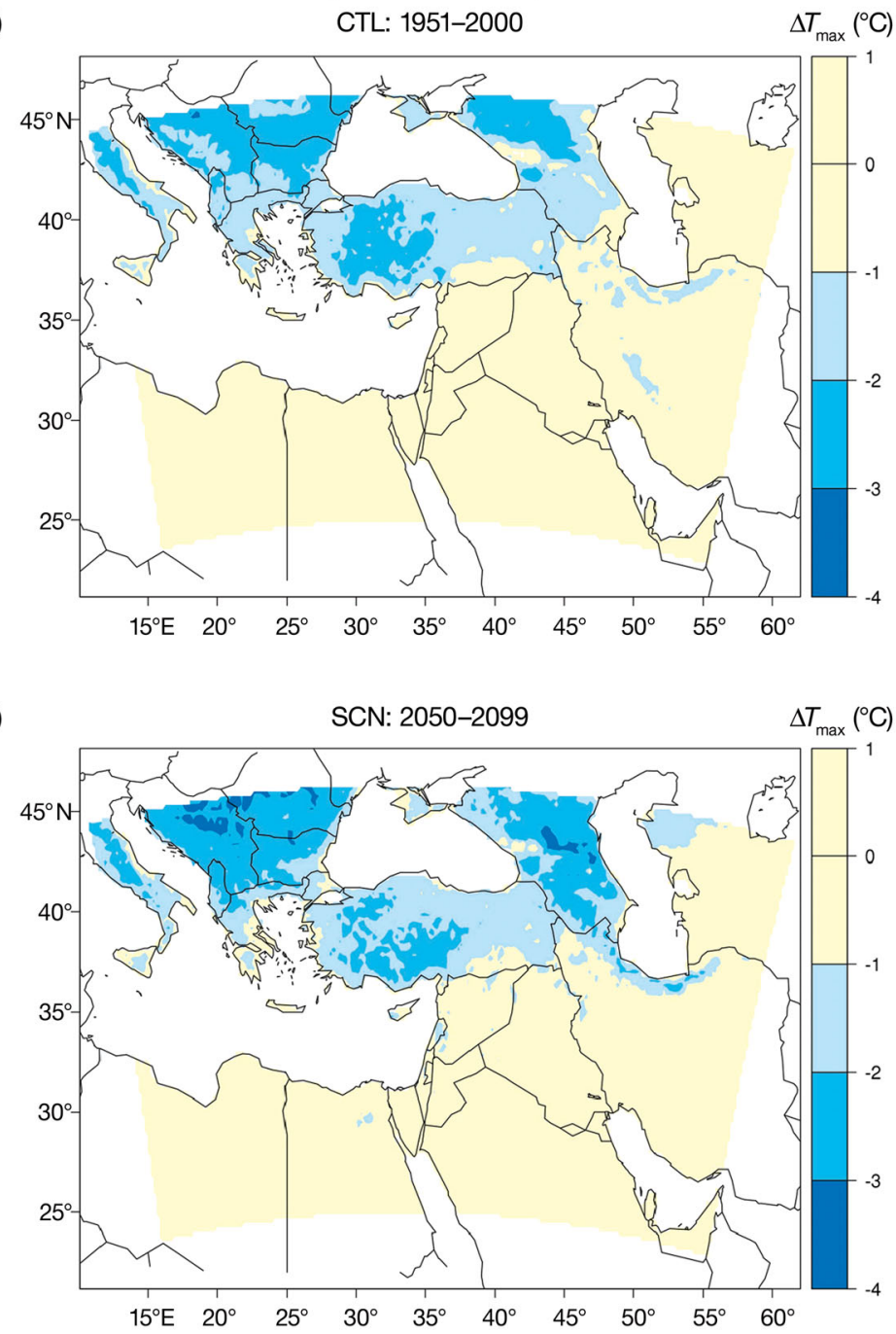

Fig. 10. Differences between driest (left) and wettest (right) $10 \mathrm{yr}$ averages and the climatology of $T_{\max }$ for the control (CTL, top) and the projection (SCN, bottom) periods

in dry and warm years, these 2 regimes showed quite similar responses. Possibly this constancy was connected with the non-dynamic vegetation scheme of the HadRM3P model and the soil properties of the land scheme, which remained unchanged throughout the simulation.

The only parameters interactively simulated by the model that can alter the evaporative regimes are either changes in the soil water content or in the amount of radiation that reaches the surface. It thus remains to be investigated whether climate-changeinduced regime alterations may occur in the future, e.g. due to vegetation and soil transformations, which could potentially add to the feedbacks between soil moisture and temperature changes. An additional aspect, not accounted for, is that increas- ing $\mathrm{CO}_{2}$ influences ET by the vegetation, which might be relevant to cloud formation and the surface energy and moisture budgets in the northern part of the EMME (de Arellano et al. 2012).

The more straightforward correlation and composite analysis results were in general agreement with the regime classification. The aforementioned sensitive regions ( $\mathrm{B}$ and $\mathrm{C}$ regimes) were the ones for which the strongest anti-correlations and the highest $T_{\text {max }}$ differences between dry and wet years were calculated. For the middle-to-end of the century, these 2 metrics indicated a small amplification of soil moisture $-T_{\max }$ coupling. This amplification was more pronounced in the Balkan region.

Since this feedback mechanism remained strong in the northern EMME, and because precipitation was 
projected to decrease and soil moisture to deplete, the present results help explain why the summer $T_{\text {max }}$ change was larger in these regions relative to that in the southern EMME. In contrast, during winter, when soil moisture was abundant, at least in the northern EMME, the warming was more spatially uniform throughout the region.

Acknowledgements. Funding was received from the European Research Council under the European Union's Seventh Framework Programme (FP7/2007-2013)/ERC grant agreement No. 226144 (C8 Project).

\section{LITERATURE CITED}

Barriopedro D, Fischer EM, Luterbacher J, Trigo RM, GarcíaHerrera R (2011) The hot summer of 2010: redrawing the temperature record map of Europe. Science 332:220-224

Black E, Blackburn M, Harrison G, Hoskins B, Methven J (2004) Factors contributing to the summer 2003 European heatwave. Weather 59:217-223

Budyko MI (1958) Heat balance of the earth's surface. U.S. Dept. of Commerce, Weather Bureau, Washington, DC

> Conti S, Meli P, Minelli G, Solimni R and others (2005) Epidemiologic study of mortality during the summer 2003 heat wave in Italy. Environ Res 98:390-399

Cox P, Betts RA, Bunton CB, Essery RLH, Rowntree PR, Smith J (1999) The impact of new land surface physics on the GCM simulation of climate and climate sensitivity. Clim Dyn 15:183-203

de Arellano J, Van Heerwaarden C, Lelieveld J (2012) Increasing $\mathrm{CO}_{2}$ suppresses boundary-layer clouds in temperate climates. Nat Geosci 5:701-704

Diffenbaugh NS, Pal JS, Giorgi F, Gao X (2007) Heat stress intensification in the Mediterranean climate change hotspot. Geophys Res Lett 34:L11706, doi:10.1029/2007 GL030000

Efthymiadis D, Goodess CM, Jones PD (2011) Trends in Mediterranean gridded temperature extremes and large-scale circulation influences. Nat Hazards Earth Syst Sci 11:2199-2214

> Feudale L, Shukla J (2011) Influence of sea surface temperature on the European heat wave of 2003 summer. I. An observational study. Clim Dyn 36:1691-1703

Fink AH, Brücher T, Krüger A, Leckebusch GC, Pinto JG, Ulbrich U (2004) The 2003 European summer heatwaves and drought-synoptic diagnosis and impacts. Weather 59:209-216

Fischer EM, Schär C (2009) Future changes in daily summer temperature variability: driving processes and role for temperature extremes. Clim Dyn 33:917-935

Fischer EM, Schär C (2010) Consistent geographical patterns of changes in high-impact European heatwaves. Nat Geosci 3:398-403

> Fischer EM, Seneviratne SI, Lüthi D, Schär C (2007) Contribution of land-atmosphere coupling to recent European summer heat waves. Geophys Res Lett 34:L06707, doi: 10.1029/2006GL029068

Giorgi F (2006) Climate change hot-spots. Geophys Res Lett 33:L08707. doi:10.1029/2006GL025734

> Grimm NB, Faeth SH, Golubiewski NE, Redman CL, Jianguo W, Xuemei B, Briggs JM (2008) Global change and the ecology of cities. Science 319:756-760

Grumm RH (2011) The Central European and Russian heat event of July-August 2010. Bull Am Meteorol Soc 92: 1285-1296

Hirschi M, Seneviratne SI, Alexandrov V, Boberg F and others (2010) Observational evidence for soil-moisture impact on hot extremes in southeastern Europe. Nat Geosci 4:17-21

IPCC (Intergovernmental Panel on Climate Change) (2007) Climate change 2007: the physical science basis. Contributions of Working Group I to the 4 th assessment report of the IPCC. Cambridge University Press, Cambridge

> Jaeger E, Seneviratne SI (2011) Impact of soil moistureatmosphere coupling on European climate extremes and trends in a regional climate model. Clim Dyn 36: 1919-1939

> Jaeger EB, Stöckli R, Seneviratne SI (2009) Analysis of planetary boundary layer fluxes and land-atmosphere coupling in the regional climate model CLM. J Geophys Res D 114:D17106, doi: 10.1029/2008JD011658

Jones P, Harris I (2008) University of East Anglia Climatic Research Unit (CRU) CRU Time Series (TS) high resolution gridded datasets. Available from NCAS British Atmospheric Data Centre at http://badc.nerc.ac.uk/ view/badc.nerc.ac.uk_ATOM_dataent_125622377332 8276

Jones RG, Noguer M, Hassell DC, Hudson D, Wilson SS, Jenkins GJ, Mitchell JFB (2004) Generating high resolution climate change scenarios using PRECIS. Met Office Hadley Centre, Exeter

Kenyon J, Hegerl GC (2008) Influence of modes of climate variability on global temperature extremes. J Clim 21: 3872-3889

Klinenberg E (2002) Heat wave: a social autopsy of disaster in Chicago. Chicago University Press, Chicago, IL

- Koster RD, Schubert SD, Suarez MJ (2009) Analyzing the concurrence of meteorological droughts and warm periods, with implications for the determination of evaporative regime. J Clim 22:3331-3341

> Kostopoulou E, Jones PD (2005) Assessment of climate extremes in the eastern Mediterranean. Meteorol Atmos Phys 89:69-85

> Kuglitsch FG, Toreti A, Xoplaki E, Della-Marta PM, Zerefos CS, Türke M, Luterbacher J (2010) Heat wave changes in the eastern Mediterranean since 1960. Geophys Res Lett 37:L04802, doi: 10.1029/2009GL041841

Laaidi K, Zeghnoun A, Dousset B, Bretin P, Vandentorren S, Giraudet E, Beaudeau P (2011) The impact of heat islands on mortality in Paris during the August 2003 heat wave. Environ Health Perspect 120:254-259

> Lelieveld J, Hadjinicolaou P, Kostopoulou E, Chenoweth J and others (2012) Climate change and impacts in the eastern Mediterranean and the Middle East. Clim Change 114:667-687

> Lelieveld J, Hadjinicolaou P, Kostopoulou E, Giannakopoulos C, Tanarhte M, Tyrlis E (in press) Model projected heat extremes and air pollution in the eastern Mediterranean and Middle East in the twenty-first century. Reg Environ Change. doi:10.1007/s10113-013-0444-4

> Meehl GA, Tebaldi C (2004) More intense, more frequent, and longer lasting heat waves in the 21st century. Science 305:994-997

> Mueller B, Seneviratne SI (2012) Hot days induced by precipitation deficits at the global scale. Proc Natl Acad Sci USA 109:12398-12403 
Mueller B, Seneviratne SI, Jimenez C, Corti T and others (2011) Evaluation of global observations-based evapotranspiration datasets and IPCC AR4 simulations. Geophys Res Lett 38:L06402, doi: 10.1029/2010GL046230

Nakicenovic N, Alcamo J, Davis G, de Vries B and others (2000) Special report on emissions scenarios. Intergovernmental Panel on Climate Change, Cambridge University Press, Cambridge

Quesada B, Vautard R, Yiou P, Hirschi M, Seneviratne SI (2012) Asymmetric European summer heat predictability from wet and dry southern winter/springs. Nat Clim Change 2:736-741

Sánchez E, Gallardo C, Gaertner MA, Arribas A, Castro M (2004) Future climate extreme events in the Mediterranean simulated by a regional climate model: a first approach. Global Planet Change 44:163-180

Seneviratne SI, Koster RD, Guo Z, Dirmeyer PA and others (2006a) Soil moisture memory in AGCM simulations: analysis of global land-atmosphere coupling experiment (GLACE) data. J Hydrometeorol 7:1090-1112

Seneviratne SI, Nichols N, Easterling D, Gooders CM and others (2012) Changes in climate extremes and their impacts on the natural physical environment. In: Field CB, Barros V, Stocker TF, Qin D and others (eds) Managing the risks of extreme events and disasters to advance climate change adaptation. A Special Report of Working Groups I and II of the Intergovernmental Panel on Cli-

Editorial responsibility: Filippo Giorgi,

Trieste, Italy mate Change. Available at: http://ipcc-wg2.gov/SREX/ images/uploads/SREX-Chap3_FINAL.pdf (accessed 20th January 2014)

> Seneviratne SI, Lüthi D, Litschi M, Schär C (2006b) Landatmosphere coupling and climate change in Europe. Nature 443:205-209

Seneviratne SI, Corti T, Davin EL, Hirschi M and others (2010) Investigating soil moisture-climate interactions in a changing climate: a review. Earth Sci Rev 99:125-161

Solberg S, Hov Ø, Isaksen ISA, Coddeville P and others (2008) European surface ozone in the extreme summer 2003. J Geophys Res 113:D07307, doi: 10.1029/2007JD 009098

Tanarhte M, Hadjinicolaou P, Lelieveld J (2012) Intercomparison of temperature and precipitation datasets based on observations in the Mediterranean and the Middle East. J Geophys Res 117:D12102, doi: 10.1029/2011JD017293

Tressol M, Ordonez C, Zbinden R, Brioude J and others (2008) Air pollution during the 2003 European heat wave as seen by the MOZAIC airliners. Atmos Chem Phys 8: 2133-2150

United Nations (Department of Economic and Social Affairs, Population Division) (2011) World population prospects: the 2010 revision. CD-ROM Edition, United Nations, New York, NY

von Storch H, Zswiers FW (1999) Statistical analysis in climate research. Cambridge University Press, Cambridge

Submitted: April 22, 2013; Accepted: October 23, 2013 Proofs received from author(s): January 21, 2014 